\title{
Levantamento de aspectos físico-químicos das águas da microbacia do mindu em Manaus-Amazonas
}

\author{
Survey of physical-chemical aspects of mindu microbacy \\ waters in Manaus-Amazonas
}

Levantamiento de aspectos físico-químicos de las aguas de microbacia del mindu en Manaus-Amazonas

\author{
Elton Alves de Souza-Filho' \\ Ieda Hortêncio-Batista ${ }^{2}$ \\ Carlossandro Carvalho de Albuquerque $e^{3}$ \\ Universidad del Estado de Amazonas (UEA) -Brasil.
}

\begin{abstract}
RESUMO
A microbacia do Mindu, principal tributário da bacia hidrográfica do São Raimundo drena parte das águas urbanas da cidade de Manaus-AM para um dos maiores rios do mundo, o rio Negro. O córrego do Mindu, comumente chamado na região por igarapé em virtude de seu canal estreito, apresenta-se sob vasta ameaça de degradação de suas águas. A grande poluição e contaminação das águas é caracterizada pelo aporte de resíduos domésticos e industriais, assoreamento de seu leito e lançamento de resíduos sólidos sobre o leito do igarapé. Com o intuito de avaliar as caracteristicas físico-químicas da qualidade das águas da microbacia do Mindu foram analisados os seguintes parâmetros: $\mathrm{pH}$, condutividade elétrica, oxigênio dissolvido, turbidez, temperatura, e sólidos dissolvidos totais realizados com auxílio de uma sonda multiparamétrica em 11 pontos de amostragem do canal principal do igarapé do Mindu. As análises de sulfetos, nitrogênio amoniacal, e fosfato total foram realizadas em laboratório. Os resultados evidenciaram que o córrego apresenta $\mathrm{pH}$
\end{abstract}

1 Maestro en Gestión y regulación de Recursos Hídricos - UEA / PROFÁGUA. Universidad del Estado de Amazonas (UEA) -Brasil. Correo electrónico: easf891@gmail.com

2 Dra. Universidad del Estado de Amazonas (UEA) -Brasil. Profesora del Máster Profesional en Gestión y Regulación de Recursos Hídricos - UEA / PROFÁGUA. Correo electrónico: iedahbatista@gmail.com

3 Dr. Universidad del Estado de Amazonas (UEA) -Brasil. Coordinador del Máster Profesional en Gestión y Regulación de Recursos Hídricos - UEA / PROFÁGUA. Correo electrónico: carlossandro.albuquerque@, gmail.com 
levemente ácido no ponto próximo as nascentes e sensivelmente alcalino nos demais trechos, teor de oxigênio dissolvido abaixo do estipulado para a legislação, caracterização de sólidos dissolvidos e suspensos que contribuem para altas concentrações de condutividade elétrica, turbidez, e sólidos dissolvidos totais. Os trechos analisados apresentaram-se ainda sob influência de aporte de efluentes domésticos e industriais com a caracterização de sulfetos, fósforo sob a forma de fosfatos e de nitrogênio na forma de nitrogênio amoniacal dissolvido nas águas.

Palavras-chave: Igarapé, Mindu, degradação, bacia.

\begin{abstract}
The Mindu microbasin, the main tributary of the São Raimundo basin drains part of the urban waters of the city of Manaus-AM to one of the largest rivers in the world, the Rio Negro. The Mindu stream, commonly called in the region by igarapé by virtue of its narrow channel, presents itself under a great threat of degradation of its waters. The great pollution and contamination of the water is characterized by the contribution of domestic and industrial waste, silting of its bed and release of solid waste on the bed of the stream. The following parameters were analyzed: $\mathrm{pH}$, electrical conductivity, dissolved oxygen, turbidity, temperature, and total dissolved solids, with the aid of a multiparameter probe at 11 points, to evaluate the physico-chemical characteristics of the water quality of the Mindu microbasin. of the main channel of the Mindu stream. Sulphide, ammoniacal nitrogen, and total phosphate analyzes were performed in the laboratory. The results showed that the stream has a slightly acidic $\mathrm{pH}$ at the point near the springs and it is sensible alkaline in the other stretches, dissolved oxygen content below that stipulated for the legislation, characterization of dissolved and suspended solids that contribute to high concentrations of electrical conductivity, turbidity, and total dissolved solids. The analyzed sections were still influenced by the contribution of domestic and industrial effluents with the characterization of sulfides, phosphorus in the form of phosphates and nitrogen in the form of ammoniacal nitrogen dissolved in the waters.
\end{abstract}

Key words: Igarapé, Mindu, degradation, basin.

\title{
Resumen
}

La microbacia del Mindu, principal tributario de la cuenca hidrográfica del São Raimundo drena parte de las aguas urbanas de la ciudad de Manaus-AM hacia uno de los mayores ríos del mundo, el río Negro. El arroyo del Mindu, comúnmente llamado en la región por igarapé en virtud de su canal estrecho, se presenta bajo una vasta amenaza de degradación de sus aguas. La gran contaminación de las aguas se caracteriza por el aporte de residuos domésticos e industriales, la sedimentación de su lecho y el lanzamiento de residuos sólidos sobre el lecho del igarapé. Con el fin de evaluar las características fisicoquímicas de la calidad de las aguas de la microcuenca del Mindu se analizaron los siguientes parámetros: $\mathrm{pH}$, conductividad eléctrica, oxígeno disuelto, turbidez, temperatura, y sólidos disueltos totales realizados con ayuda de una sonda multiparamétrica en 11 puntos de muestreo del canal principal del igarapé del Mindu. Los análisis de sulfuros, nitrógeno 
amoniacal, y fosfato total se realizaron en laboratorio. Los resultados evidenciaron que el arroyo presenta $\mathrm{pH}$ levemente ácido en el punto próximo a las nacientes y sensiblemente alcalino en los demás fragmentos, contenido de oxígeno disuelto bajo el estipulado para la legislación, caracterización de sólidos disueltos y suspendidos que contribuyen a altas concentraciones de conductividad eléctrica, turbidez, y sólidos disueltos totales. Los extractos analizados se presentaron todavía bajo influencia de aporte de efluentes domésticos e industriales con la caracterización de sulfuros, fósforo en forma de fosfatos y de nitrógeno en la forma de nitrógeno amoniacal disuelto en las aguas.

Palabras clave: Igarapé, Mindu, degradación, cuenca.

\section{Introdução}

No âmbito deste estudo é retratado às condições de poluição e contaminação das águas da microbacia do igarapé do Mindu, principal curso da bacia hidrográfica do São Raimundo, localizada na cidade de Manaus, no coração da floresta Amazônica. A contaminação dos principais igarapés ou córregos da zona urbana de Manaus é reflexo de uma ocupação desenfreada que ocorreu após a eclosão e desenvolvimento da zona franca ou distrito industrial da cidade de Manaus, a capital do Amazonas, localizada no norte do Brasil conforme apresenta a Figura 1. A cidade embora esteja às margens do maior rio do mundo, o rio Amazonas, além claro de estar também as margens de outro dos maiores do mundo, o rio Negro, e estar entrecortada por uma vasta rede hidrográfica de igarapés por toda a cidade, apresenta um quadro sensível de contaminação das águas em seu trecho urbano.

Ainda que a cidade possua abundância de água por todos os lados, em outro as condições de saneamento e infraestrutura de rede e coleta de esgoto ficam a desejar, o que vem a colocar uma ótica de resultados insatisfatórios encontrados para a qualidade das águas de inúmeros córregos urbanos estudados durante o decorrer dos últimos anos, entre estes o igarapé do Mindu, nosso objeto de estudo neste trabalho.

As condições de saneamento e infraestrutura de rede e coleta de esgoto são deficitárias, estando a cidade, inclusive,entre as piores do Brasil em saneamento básico e esgotamento sanitário. A cidade ocupa o $96^{\circ}$ lugar no ranking de saneamento realizado entre os 100 (cem) maiores municípios brasileiros conforme o Instituto Trata Brasil (2018). Entre as características deste ranking a cidade foi destacada entre os 10 (dez) municípios 
Figura 1 - Mapa da localização da cidade de Manaus-AM no estado do Amazonas.

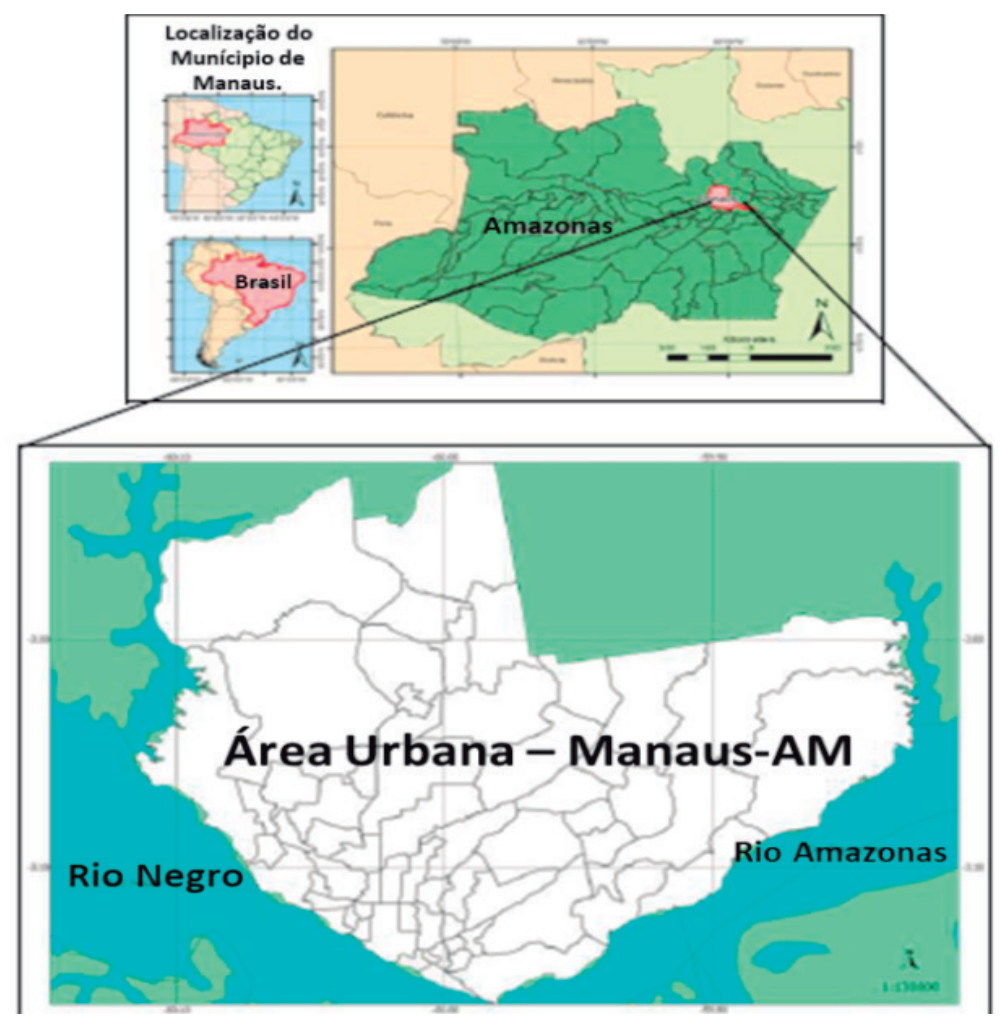

Fonte: Cassiano (2013,pg. 24).

com mais deficiência na coleta de esgoto com apenas 10,18\% de atendimento, ou seja, o restante que não é coletado para tratamento "Manaus lança diretamente $89,82 \%$ de esgoto in natura nas águas", com predominância nos córregos urbanos da cidade, área de drenagem da cidade e meios de diluição destes efluentes, o que culmina por apresentar alta contaminação e poluição destes rios da cidade

Para reforçar esta característica verificamos que Pinto et al. (2009, pg. 628) enfatizou que;

Na região amazônica a contaminação dos igarapés está se tornando um dos problemas mais relevantes, pois, além da poluição visual, vem crescendo, em importância, a contaminação dos recursos hídricos por metais tóxicos 
cujos tratamentos são difíceis e caros. Este tipo de efeito vem sendo observado, também, nos igarapés urbanos de Manaus, capital do Amazonas, os quais são tributários do rio Negro, principal agente de drenagem da cidade (PINTO et al., 2009, pg. 628).

Ferreira et al. (2012, pg. 534) evidenciou que a expansão urbana de Manaus tem ocorrido de forma horizontal, a partir da região central metropolitana, nas direções norte, leste e oeste, sendo contida apenas por barreiras naturais, no caso, o rio Negro, Amazonas e Tarumã, ou por áreas públicas de grande relevância destacadas para fins específicos, como a Reserva Florestal Adolpho Ducke e as terras do Exército brasileiro. Esta tem sido a forma de expansão urbana do município. Em espaço de tempo relativamente curto, a cidade viu seu imenso número de igarapés tornarem-se visivelmente degradados. No mapa da Figura 2 apresenta-se o avanço da expansão urbana desde a implantação da zona franca de Manaus, na década de 70, até o ano de 2008, onde se verifica o avanço partindo da região portuária (centro) para as zonas leste e norte da cidade.

Figura 2 - Mapa do crescimento urbano de Manaus-AM de 1973 até 2008.

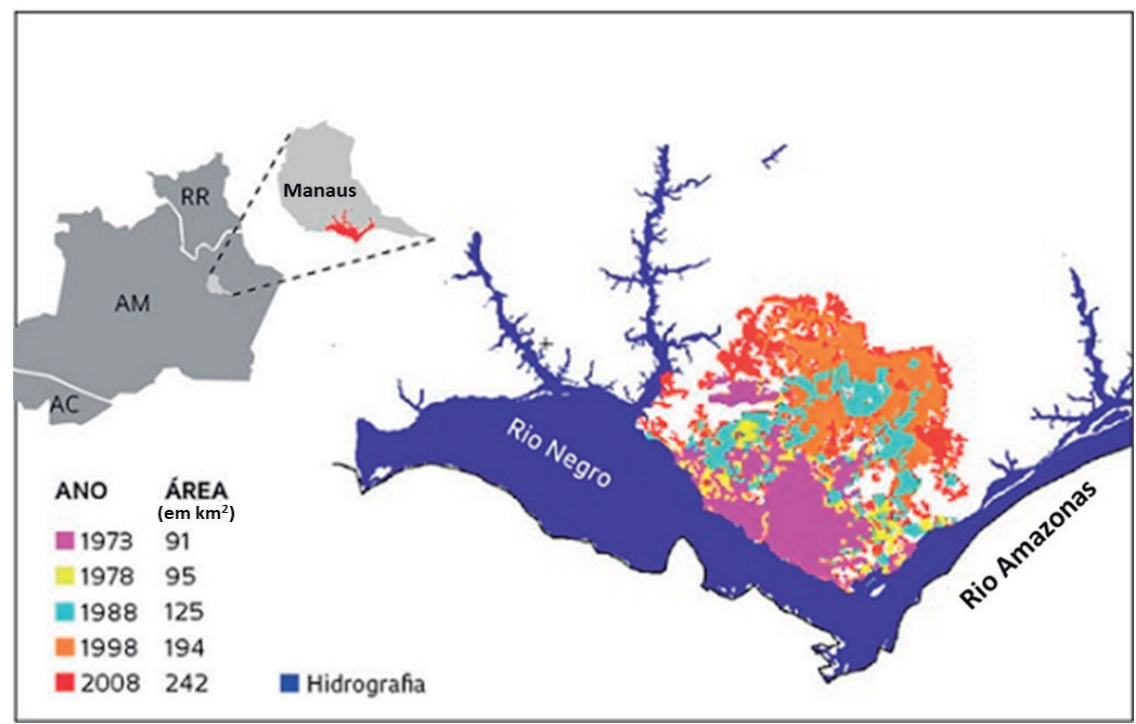

Fonte: Souza et al. (2015, pg. 1112). 
$\mathrm{Na}$ composição hidrográfica da cidade de Manaus Ferreira et al. (2012, pg. 534) descreve que na área urbana estão localizadas quatro grandes bacias hidrográficas, sendo duas delas inteiramente urbanizadas (São Raimundo e Educandos), e as outras duas apenas parcialmente (Puraquequara e Tarumã), constituindo uma rede hidrográfica com uma malha de drenagem complexa.

Conforme denota Borges e Santos (2011, pg. 3) a ocupação desordenada de parte desta bacia ao longo de décadas resultou em uma série de problemas ambientais e sociais possibilitando condições insalubres aos seus moradores. Como consequência, igarapés e cursos d'água têm sido poluídos, assoreados e obstruídos tanto pela derrubada da vegetação quanto pela presença de grande quantidade de lixo, resultante da construção de moradias nas suas margens, e expansão da zona urbana sobre os recursos hídricos e vegetação localizados na cidade.

O presente trabalho tem como objetivo realizar a caracterizaçãos dos aspectos físicos e químicos de $\mathrm{pH}$, condutividade elétrica, temperatura, sólidos dissolvidos totais, oxigênio dissolvido, nitrogênio amoniacal, fosfato total, sulfetos, e turbidez de 11 (onze) pontos de amostragem realizados nos períodos sazonais de vazante e cheia do Igarapé do Mindu.

\section{Área de estudo}

A bacia hidrográfica do São raimundo é caracterizada por sua intrincada malha hidrográfica que corta toda a cidade, com predominância na área urbana, do qual apresenta estado crítico de degradação de seus corpos receptores. O seu principal tributário, o Igarapé do Mindu, em seus aproximadamente $22 \mathrm{~km}$ de extensão, corta a cidade no sentido nordeste-sudoeste (Figura 3), tem-se apresentado num estado crítico de poluição e contaminação de suas águas, desde suas três nascentes protegidas sob decreto municipal que criou o Parque Municipal Nascentes do Mindu, em seu alto curso.

Seguindo até o médio curso deste rio, esta localizado o Parque Municipal do Mindu, área de preservação permanente, que faz parte através de Decreto municipal de 2007 do corredor ecológico do Mindu, do qual estão inseridos os bairros centrais deste curso, como o Conjunto Petros, do qual se apresenta em estado de contaminação predominantemente por efluentes domésticos, leito comprometido por assoreamento e descaracterização da 
vegetação ciliar. No baixo curso do igarapé está localizado o Parque Municipal dos Bilhares, na foz do curso, nas proximidades do encontro com o rio Negro, evidenciado conforme Figura 3.

Figura 3 - Mapa da microbacia do igarapé do Mindu.

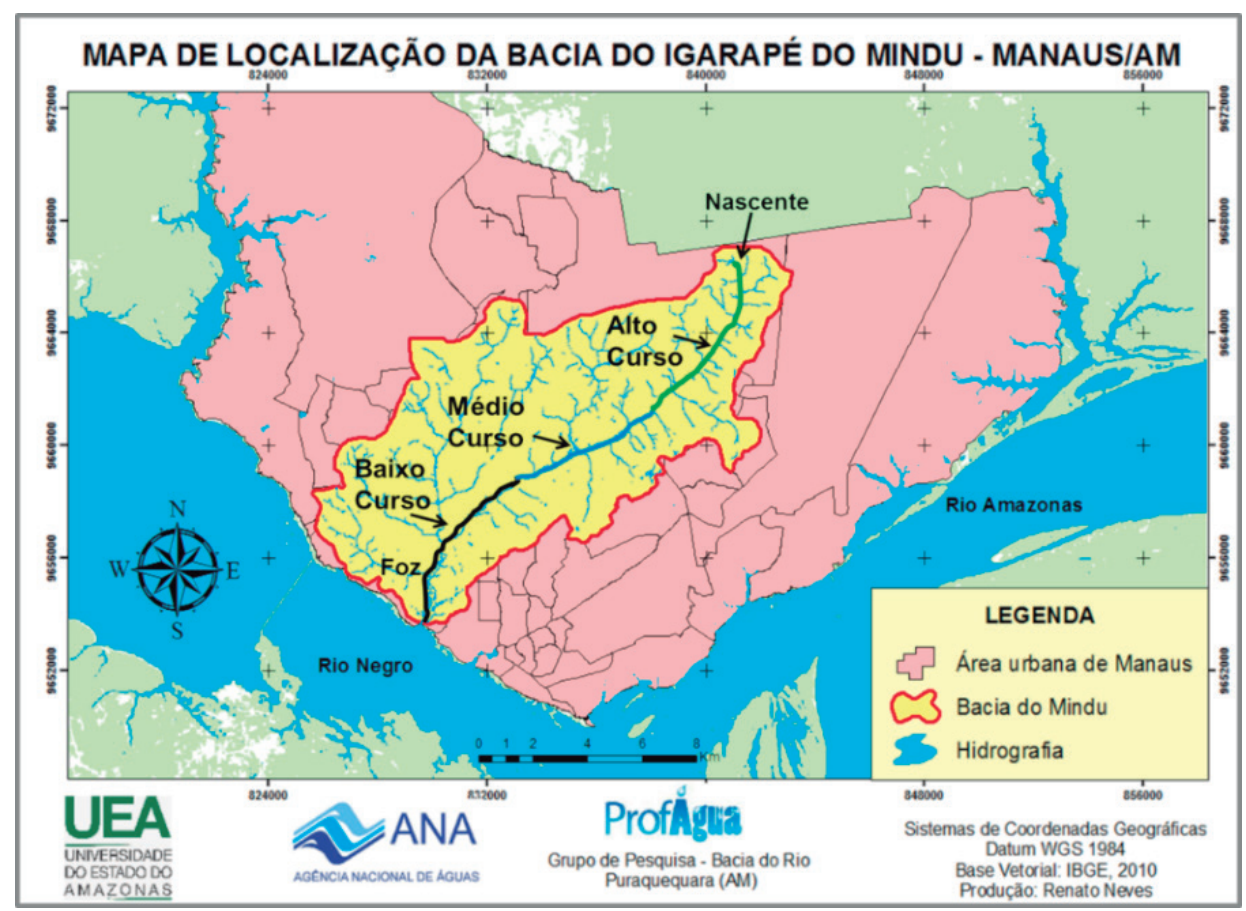

Fonte: Elaboração própria do autor (2018).

\section{Metodologia}

Para a realização das coletas de campo e análises foram utilizadas metodologias já bastante difundidas em análises de água, como a "Standard Methods for the examination of water and wastewater (APHA)", além do que está sendo disseminado pela Agência Nacional de Águas do Brasil - ANA, através da elaboração da resolução ANA n 724/2011 em parceria com a companhia de saneamento de São Paulo - CETESB. Esses órgãos tem como objetivo a padronização das análises desde sua coleta, preservação das amostras, análises de campo e em laboratório, com o intuito de desenvolver e aprimorar os estudos de qualidade da água para a maior quantidade de estados e municípios do Brasil. 
Foram selecionados 11 (onze) pontos na etapa de planejamento, previamente referenciados por coordenadas geográficas. Os pontos selecionados e as coordenadas são apresentados na Tabela 1 .

Tabela 1 - Identificação dos pontos de amostragem do Igarapé do Mindu.

\begin{tabular}{|c|c|c|}
\hline Ponto de Coleta & Coordenadas geográficas & Localização em Manaus \\
\hline Saída Nascentes do Mindu (P1) & $3^{\circ} 00^{\prime} 36.8^{\prime \prime}$ 'S e $59^{\circ} 56^{\prime} 02.6^{\prime \prime} \mathrm{W}$ & Jorge Teixeira (Alto curso) \\
\hline Avenida Itaúba (P2) & $3^{\circ} 02^{\prime} 14.6^{\prime \prime}$ S e $59^{\circ} 56^{\prime} 14.7^{\prime \prime} \mathrm{W}$ & Jorge Teixeira (Alto curso) \\
\hline Avenida Autaz Mirim (P3) & $3^{\circ} 02^{\prime} 37.5^{\prime \prime} \mathrm{S}$ e $59^{\circ} 56^{\prime} 31.2^{\prime \prime} \mathrm{W}$ & São José (Alto curso) \\
\hline Novo Aleixo (P4) & $3^{\circ} 03^{\prime} 05.5^{\prime \prime}$ S e $59^{\circ} 57^{\prime} 01.7^{\prime \prime} \mathrm{W}$ & Novo Aleixo (Médio curso) \\
\hline SESI (P5) & $3^{\circ} 03^{\prime} 42.7^{\prime \prime}$ S e $59^{\circ} 57^{\prime} 39.7^{\prime \prime} \mathrm{W}$ & Coroado (Médio curso) \\
\hline Conjunto Petros (P6) & $3^{\circ} 04^{\prime} 28.1^{\prime \prime S}$ e $59^{\circ} 58^{\prime} 57.8^{\prime \prime} \mathrm{W}$ & Aleixo (Médio curso) \\
\hline Parque Municipal do Mindu (P7) & $3^{\circ} 04^{\prime} 55.0^{\prime \prime S}$ e $60^{\circ} 00^{\prime} 13.7^{\prime \prime} \mathrm{W}$ & Parque Dez (Médio curso) \\
\hline Passeio do Mindu (P8) & $3^{\circ} 05^{\prime} 21.7^{\prime \prime S}$ e $60^{\circ} 00^{\prime} 45.3^{\prime \prime} \mathrm{W}$ & Parque Dez (Médio curso) \\
\hline UEA/EST (P9) & $3^{\circ} 05^{\prime} 29.9^{\prime}$ 'S e $60^{\circ} 00^{\prime} 55.1^{\prime \prime} \mathrm{W}$ & Parque Dez (Baixo curso) \\
\hline Parque dos Bilhares (P10) & $3^{\circ} 06^{\prime} 09.0^{\prime \prime} \mathrm{S}$ e $60^{\circ} 01^{\prime} 41.4^{\prime \prime} \mathrm{W}$ & Chapada (Baixo curso) \\
\hline São Jorge (P11) & $3^{\circ} 06^{\prime} 48.8^{\prime \prime} \mathrm{S}$ e $60^{\circ} 01^{\prime} 54.0^{\prime \prime} \mathrm{W}$ & São Jorge (Baixo curso) \\
\hline
\end{tabular}

Fonte: Elaboração própria do autor (2018).

Na Figura 4 é possível identificar cada ponto de coleta no curso do igarapé do Mindu partindo do ponto P1 - área de nascente, até o ponto P11 área de localização da foz do curso.

O principal critério de seleção dos pontos de amostragem foi à acessibilidade, para que os procedimentos de coleta e transporte de equipamentos pudessem ser realizados. Outro critério de seleção foi a avaliação visual de impacto de influência antrópica. Foi utilizado como ferramenta de auxílio o "Google Maps" para localização dos pontos de amostragem no mapa da zona urbana de Manaus e o "Google Street View" para determinação das condições de acesso aos pontos de amostragem conforme Figura 5. 
Elton Alves de Souza-Filho - Ieda Hortêncio-Batista

Levantamento de aspectos físico-químicos das águas da microbacia do mindu em Manaus-Amazonas

Figura 4 - Identificação dos pontos de amostragem no curso do igarapé do Mindu.

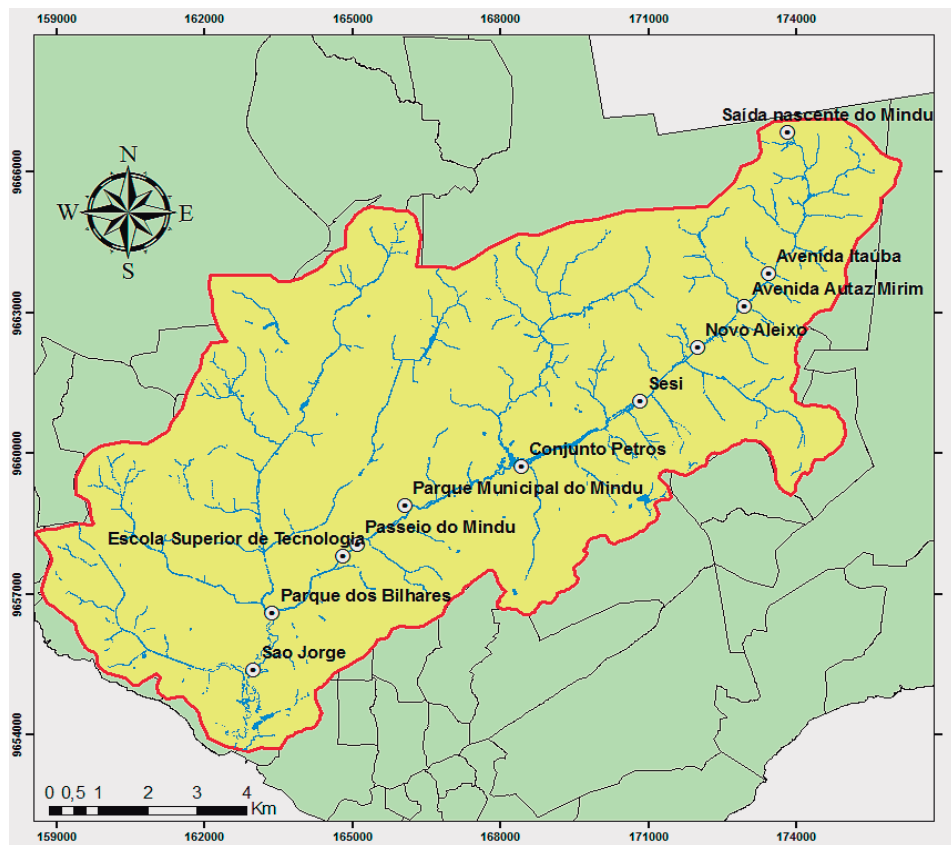

\section{MAPA DA REDE \\ DE AMOSTRAGEM DA ÁREA DE ESTUDO \\ Legenda}

$\odot$ Pontos de Amostragem

Rede Hidrográfica

Bacia do Mindu Bairros da cidade de Manaus

PONTOS DEAMOSTRAGEM

P1 Saida Nascente do Mindu P2 Avenida Itaúba

P3 Avenida Autaz Mirim

P4 Novo Aleixo

P5 Sesi

P6 Conjunto Petros

P7 Parque Municipal do Mindu

P8 Passeio do Mindu

P9 Escola Superior de Tecnologia P10 Parque dos Bilhares

P11 São Jorge

Sistema de Coordenadas Geográfic as Datum WGS 1984 Base Vetorial: IBGE, 2010 Produção: Renato Neves

\section{UEA}

UNIVEASIDADE Prof: PIIME
DOESTADODO
AMAZONAS

Fonte: Elaboração própria do autor (2018).

Figura 5- Modelo de vista utilizada na etapa de planejamento com o Google Street View para acessar o local de amostragem P6 - Conjunto Petros.

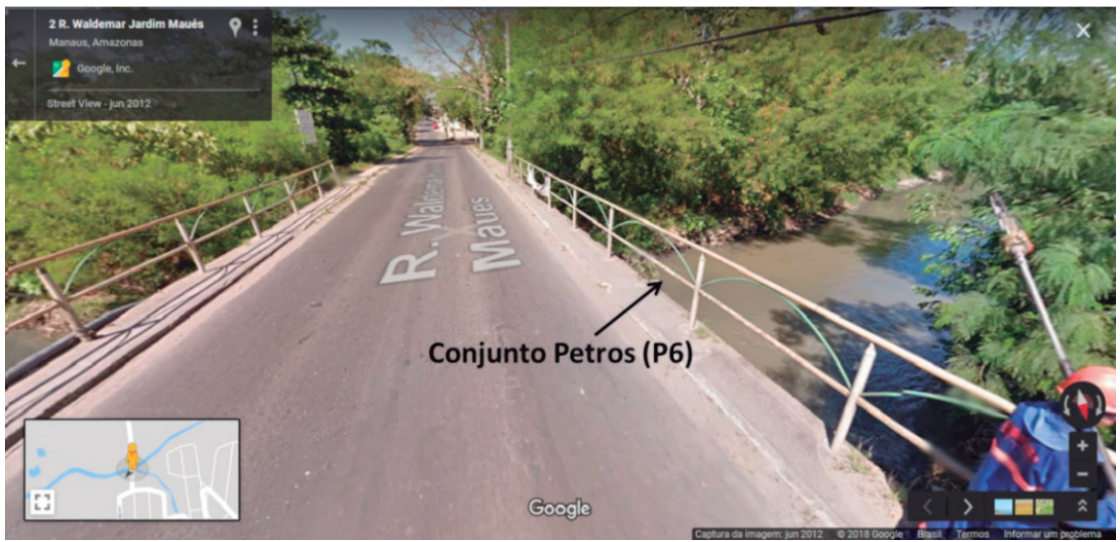

Fonte: Elaboração própria do autor (2018). 
Em termos de frequência da amostragem, foram realizadas coletas durante os meses de julho e outubro de 2017, no periodo de vazante, ou seja, de poucas chuvas em Manaus-AM, e durante o mês de janeiro e abril de 2018 no periodo chuvoso, conforme dados de precipitação para o ano de 2017 e 2018 dispostos na Figura 6. Os pontos em vermelho destacam os períodos de coleta do estudo.

Figura 6 - Dados de precipitação em Manaus no ano de 2017 e 2018.

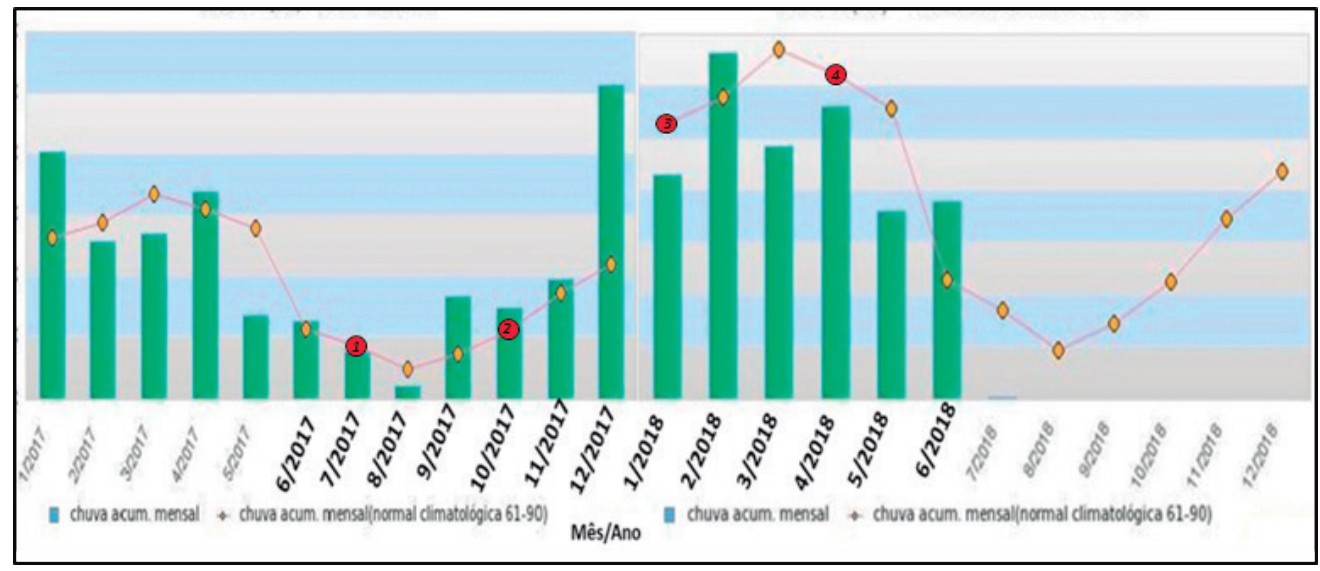

Fonte: Instituto Nacional de Meteorologia - INMET

As coletas e análises foram realizadas conforme as metodologias descritas na Resolução ANA no 724/2011, a qual define o "Guia Nacional de Coleta e Preservação de Amostras de Água, Sedimentos, Comunidades aquáticas e Efluentes líquidos" sendo este o documento de referência técnica para disciplinar os procedimentos de coleta e preservação de amostras de águas superficiais em todo o território nacional. Os equipamentos de campo foram calibrados antes da coleta do campo, sendo pelo menos 1 (um) dia antes da realização do mesmo. Realizou-se a calibração conforme seus respectivos parâmetros físico-químicos e seguindo o manual recomendado pelo fabricante com a utilização das soluções tampão de $\mathrm{pH}=4, \mathrm{pH}=7,0$ e $\mathrm{pH}=10,0$, solução de condutividade $1413 \mathrm{uS} . \mathrm{cm}^{-1}$, solução padrão zero 
de oxigênio dissolvido a base de sulfito de sódio e soluções de 0 NTU, 10 NTU e 500 NTU para calibração do medidor de turbidez.

As análises de $\mathrm{pH}$, condutividade elétrica, temperatura da água, oxigênio dissolvido, e turbidez que de acordo com o artigo 14 no parágrafo $3^{\circ}$ da resolução ANA n ${ }^{\circ} 724 / 2011$, devem ser avaliados no ponto de amostragem. Tais análises foram realizadas com o auxílio de um equipamento portátil (sonda multiparamétrica de marca HANNA HI 98194) conforme Figura 7-A e B. A análise de turbidez também foi realizada no campo no momento da coleta, onde se utilizou do equipamento turbidímetro HANNA HI 93703C conforme Figura 7-C abaixo.

Figura 7 - Sonda multiparamétrica (A e B) e medidor de turbidez (C) utilizados para medição de variáveis físico-químicas.

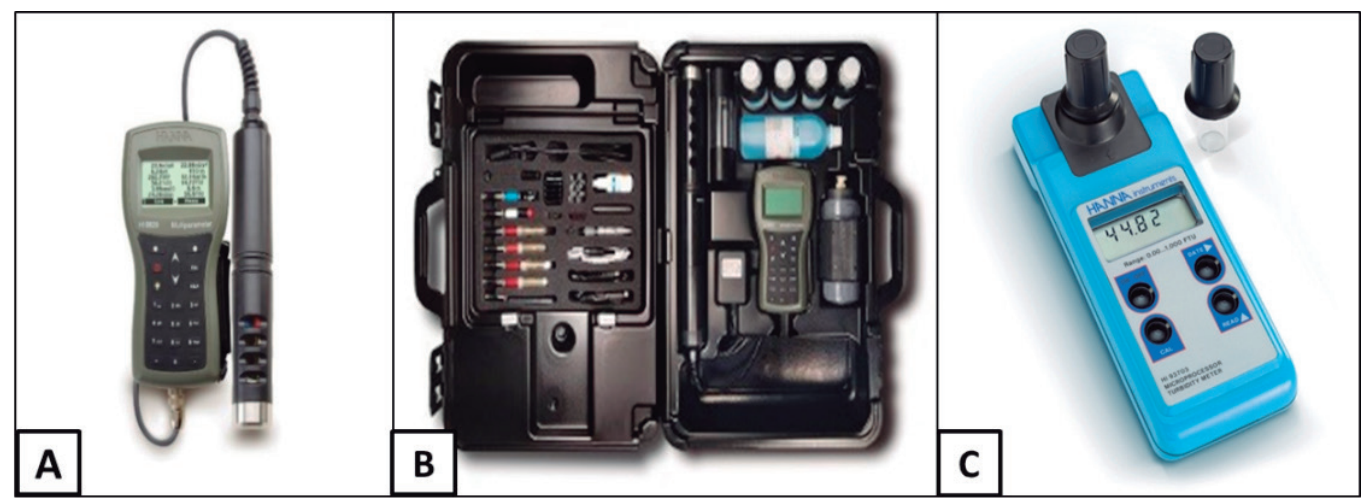

Fonte: Elaboração própria do autor (2018).

A etapa de coleta de água foi realizada na zona superficial do igarapé e a medição realizada com o acesso da sonda multiparamétrica na água. Nos pontos de difícil acesso de coleta, como por exemplo, o ponto P6 (Conjunto Petros) utilizou-se de um balde em inox para lançamento através de uma ponte localizada nas proximidades do curso (Figura 8). 
Figura 8 - Amostra coletada com balde da zona superficial do Igarapé. Em (A) equipamentos e materiais utilizados na coleta de campo (B) medição e registro dos dados; (C) sonda em contato com amostra.

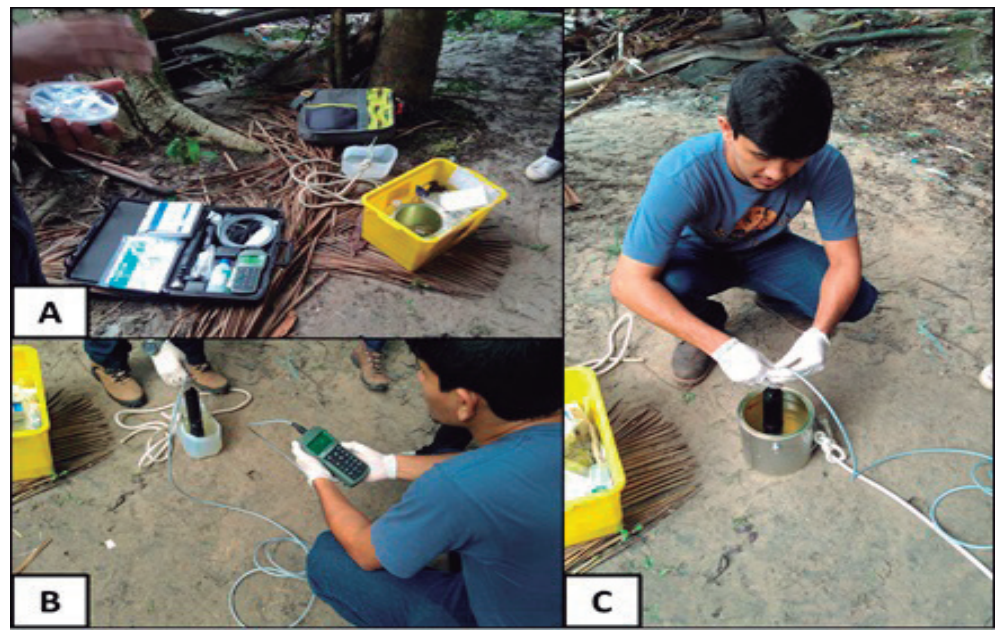

Fonte: Elaboração própria do autor (2018).

As análises de amônia ou nitrogênio amoniacal, sulfetos e fosfato total foram realizadas conforme descritas em APHA (Standard methods for the examination of water and wastewater), realizadas em laboratório. As metodologias empregadas para cada análise e equipamentos de laboratório utilizados estão dispostos na Tabela 2.

Tabela 2 - Metodologias utilizadas em análises de laboratório.

\begin{tabular}{ccc}
\hline Metodologia utilizada & Análise & Equipamento utilizado \\
\hline $\begin{array}{c}\text { APHA 4500-NH3 D/1997 - Am- } \\
\text { monia-Selective Electrode Method }\end{array}$ & Amônia & Metrohm 781 pH/Ion meter \\
$\begin{array}{c}\text { APHA 4500-P E/1999 - Stan- } \\
\text { dard Methods - 4500 P E/1999 }\end{array}$ & Fosfato Total & Espectrofotômetro Hach DR \\
- Phosphorus & & 3900 \\
APHA 4500 D/2011 & & \\
$\begin{array}{c}\text { Standard Methods for the examina- } \\
\text { tion of water and wastewater 4500 } \\
\text { sulfide }\end{array}$ & Sulfetos & Espectrofotômetro Hach DR \\
\hline
\end{tabular}

Fonte: Elaboração própria do autor (2018). 
Os dados levantados foram dispostos em planilha Excel, onde em seguida realizou-se a média aritmética simples para cada análise que foi realizada dentro do respectivo período de 3 (três) meses entre uma coleta e outra, totalizando desta forma o estudo em 12 (doze) meses e 4 (quatro) coletas.

\section{Resultados e Discussões}

Durante este estudo verificou-se que a área de preservação das nascentes do igarapé do Mindu apresenta lançamento de resíduos sólidos já em seu entorno, ou seja, logo na saída do parque criado para a preservação destas nascentes, além do que já foi construído um bueiro que lança água proveniente de lançamento de esgoto diretamente no leito do igarapé. Através da realização de análises físicas, químicas e biológicas, perpassando por 11 (onze) pontos de locais de coleta, da nascente a foz do igarapé do Mindu, a qualidade da água nestes pontos apresentaram impactos de fonte antrópica, com inúmeros pontos sendo possível a identificação visual e quantitativa da degradação do córrego, com fortes impactos de assoreamento do leito, descaracterização da mata ciliar, e falta de efetividade do poder público para atuar em pontos com impactos de origem orgânica e industriais, características essas impostas sob baixa coleta e tratamento de esgoto da cidade de Manaus.

\section{Potencial Hidrogeniônico (pH)}

$\mathrm{O}$ pH apresentou oscilação nos pontos avaliados em relação a vazante e cheia, com valores mínimos encontrados no ponto de água com características naturais (P1) entre 6,44-6,76 possuindo características levemente ácidas e águas de cor escura, característico da presença de ácidos húmicos e fúlvicos que conferem estas características as águas do Igarapé do Mindu e demais cursos com nascentes na floresta amazônica e que posteriormente deságuam no rio Negro (SIOLI e KLINGE, 1962, pg. 28). Os demais pontos avaliados apresentaram características básicas com $\mathrm{pH}$ oscilando a valores de 6,87 - 7,23, com predomínio dos valores básico nos cursos médio e curso baixo do igarapé, sobretudo no período de cheia conforme o gráfico da Figura 9. Usando a análise estatística sobre os pontos avaliados verificou-se que a média aritmética oscilou entre $6,6-7,08$, apresentando desvio padrão entre $0,025-0,1530$. 
Figura 9 - Gráfico de $\mathrm{pH}$ para os pontos analisados de P1 a P11.

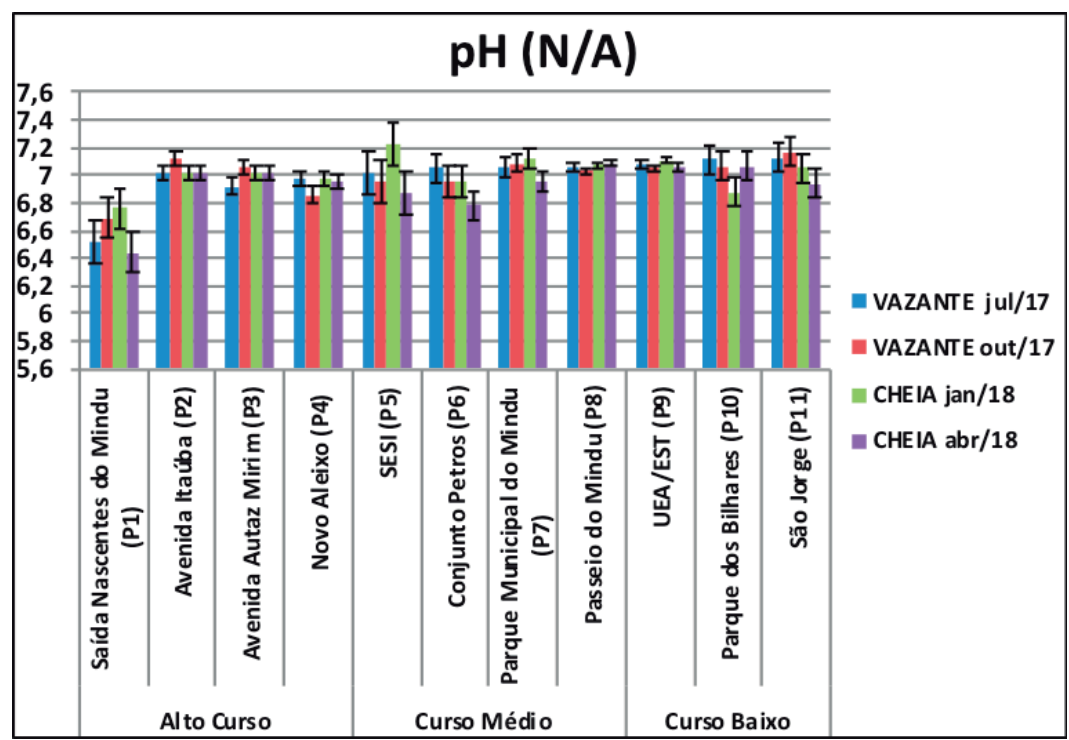

Fonte: Elaboração própria do autor (2018)

No enquadramento da Resolução CONAMA 357/2005 o pH para águas de Classe II, caso do Igarapé do Mindu, o preconizado pela legislação apresenta variação entre $6,0-9,0$. Os rios amazônicos e seus tributários de cor escura em suas condições naturais apresentam características ácidas 4,0 - 5,6 com alterações acima destes dados relacionadas a modificações antrópicas (Melo et al. (2005, pg. 43).

\section{Temperatura da Água}

A temperatura da água apresentou oscilação de $26,38-32,4{ }^{\circ} \mathrm{C}$ (Figura 10) com menores valores encontrados no $\mathrm{P} 1$, e os demais dados apresentaram acréscimo de temperatura no período de vazante em relação ao período de cheia com discreta diferença. Melo et al. (2005, pg. 43) obteve valores variando entre 26,0 a $29,3^{\circ} \mathrm{C}$ em trechos do igarapé do Mindu e relacionou os altos valores de temperatura a falta da mata ciliar do igarapé, oxidação biológica da matéria orgânica e lançamento de despejos industrial e doméstico nas águas. 
Figura 10 - Gráfico da temperatura para os pontos analisados de P1 a P11.

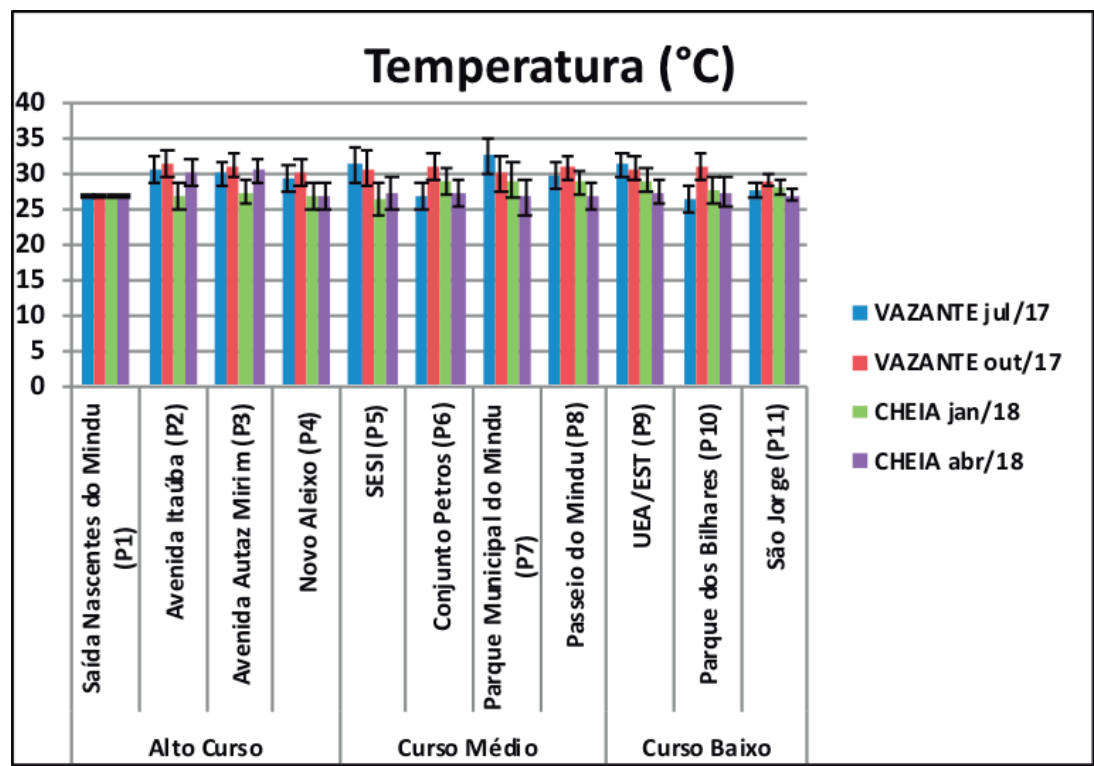

Fonte: Elaboração própria do autor (2018)

Os dados médios da temperatura oscilaram entre $26,86-29,65{ }^{\circ} \mathrm{C}$ com desvio padrão entre $0,10-2,42$. Os altos valores para temperatura podem ser fatores favoráveis para a redução da concentração de oxigênio dissolvido, pois, com a elevação da temperatura e diminuição da pressão, ocorre redução da solubilidade de oxigênio na água . Almeida et al. (2017, pg. 213) destacou que no curso médio do Igarapé do Mindu, por ser uma zona de alta urbanização, o volume de matéria orgânica (vindo dos esgotos), juntamente com a decomposição de plantas aquáticas, a intensa atividade microbiológica e a elevada temperatura, indicam que possivelmente são fatores que contribuem para o baixo teor de oxigênio nessas águas.

\section{Condutividade Elétrica}

Para os valores obtidos para o parâmetro condutividade elétrica, em gráfico na Figura 11, verificou-se que os dados obtidos apresentaram-se com menor valor no ponto (P1) localizado nas saídas das nascentes cuja 
água possui coloração escura, possui ainda a melhor condição de suas águas naturais e pouco modificado por fonte antrópica.

Figura 11 - Gráfico do parâmetro analisado condutividade elétrica nos pontos de P1 a P11.

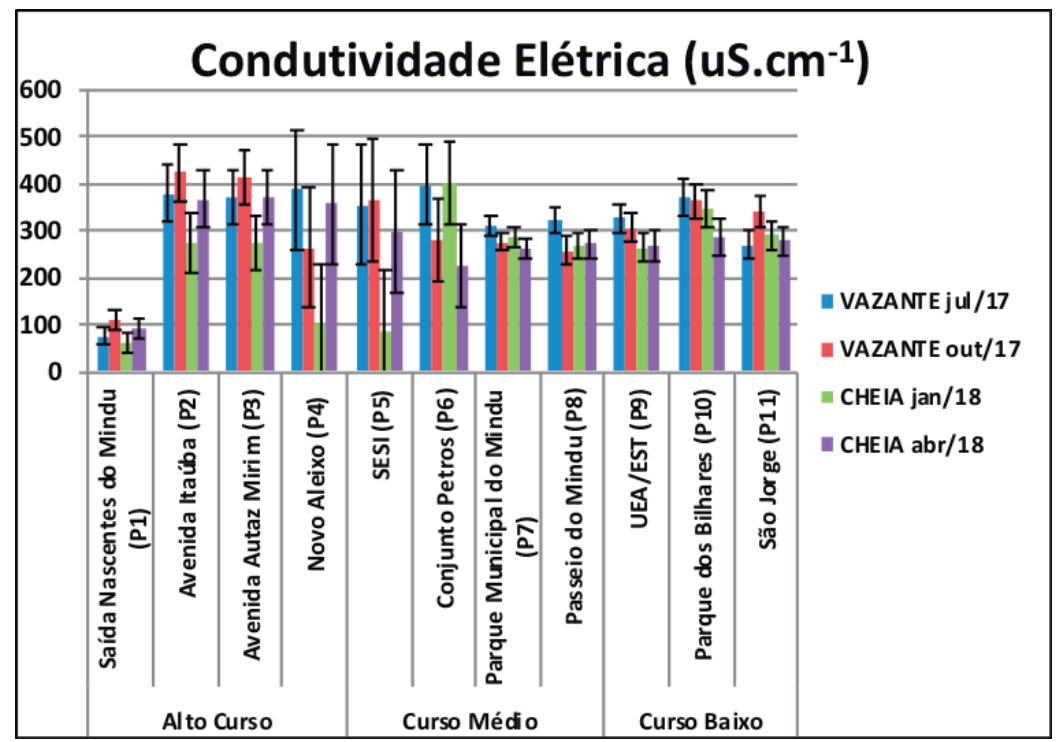

Fonte: Elaboração própria do autor (2018).

A média aritmética oscilou entre $84,25-360,75$ uS.cm ${ }^{-1}$. O desvio padrão apresentou variação de 20,07 - 129,83. Os altos valores podem estar relacionados com a grande variação de lançamentos de efluentes domésticos, resíduos sólidos e efluentes industriais despejados de forma pontual nas águas (Melo et al., 2005, pg. 43), todavia de prolongada autodepuração nas águas, e cujos poluentes são gradualmente sedimentados e carreados nas águas. Esta característica de assoreamento nas águas sofre grande influência sazonal com aumento da concentração destes sólidos no período de vazante. Ainda assim o maior volume de águas no período de cheia é responsável pela transferência destes sólidos com maior eficiência do curso alto (maior desvio padrão) para as áreas mais baixas (declividade) do Igarapé do Mindu, concentrando grande parte destes poluentes no curso baixo no Pq. dos Bilhares (P10) no São Jorge (P11) na zona de foz 
com o rio Negro. Os maiores valores para este parâmetro foi encontrado nos pontos da avenida itaúba, avenida autaz mirim e conjunto Petros, cuja alta condutividade pode estar associada ao assoreamento (Figura 12 - B) e retirada da vegetação ciliar.

Figura 12 - Águas do igarapé do Mindu, no ponto P7 (A) e ponto P6 (B) no conjunto Petros sob ação antrópica de remoção da mata ciliar e assoreamento do leito do igarapé.

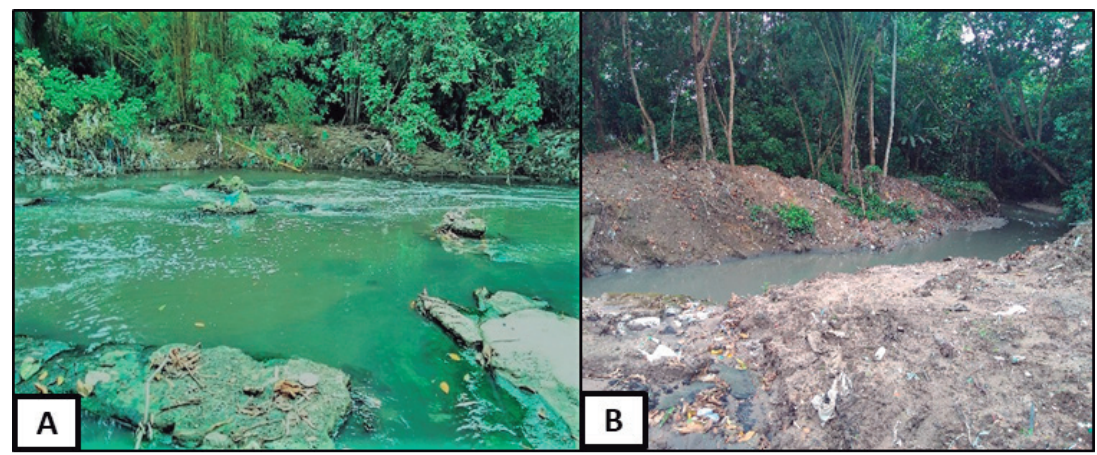

Fonte: Elaboração própria do autor (2018).

\section{Oxigênio Dissolvido}

$O$ oxigênio dissolvido representa a característica do oxigênio do ar $\mathrm{O}_{2(\mathrm{~g})}$ apresentar-se dissolvido nas águas $\mathrm{O}_{2(\mathrm{aq})}$, permitindo o equilíbrio da vida aquática e propiciando a realização de fotossíntese pelos organismos vegetais. A concentração de oxigênio dissolvido no ponto P1 - Águas de nascentes do córrego apresentou variação entre 3,38 - 4,05 mg.L.-1 (Figura 13). A linha vermelha (Figura 13) representa o valor de referência preconizado pela legislação CONAMA 357/2005 para rios de Classe II com limite de $>5,0 \mathrm{mg} . \mathrm{L}^{-1}$. Os valores obtidos para este ponto na concentração de oxigênio dissolvido são característicos das águas amazônicas para rios de águas pretas, que possuem maior quantidade de material orgânico dissolvido (SIOLI e KLINGE, 1962, pg.28).

Os demais pontos avaliados tanto na vazante e na cheia apresentaram-se abaixo dos limites de referência CONAMA, possuindo predominantemente no período avaliado concentrações abaixo de $<2,64 \mathrm{mg} . \mathrm{L}^{-1}$ 
(Figura 13), possuindo desta forma consequências na qualidade das águas. Melo et al. (2005, pg. 44) analisando estes trechos do Igarapé do Mindu obteve teores médios deste parâmetro $<2,38 \mathrm{mg} . \mathrm{L}^{-1}$ e relacionou estes valores à decomposição da matéria orgânica proveniente de despejo industrial e esgotos domésticos.

Almeida et al. (2017, pg. 213) destacou que à medida que o trecho alcança o curso médio para o curso inferior do Igarapé do Mindu os valores de oxigênio dissolvido diminuem variando de 1,75 a 3,6 mg. $\mathrm{L}^{-1}$, principalmente as águas do Corredor Ecológico Urbano do Igarapé Mindu (Médio Curso), possivelmente ocasionada por entrada de efluentes (matéria orgânica) que são lançados diretamente no igarapé, sem nenhum tipo de tratamento, advindos da urbanização gerada no entorno do corpo hídrico.

Figura 13 - Gráfico do parâmetro analisado de oxigênio dissolvido nos pontos de P1 a P11.

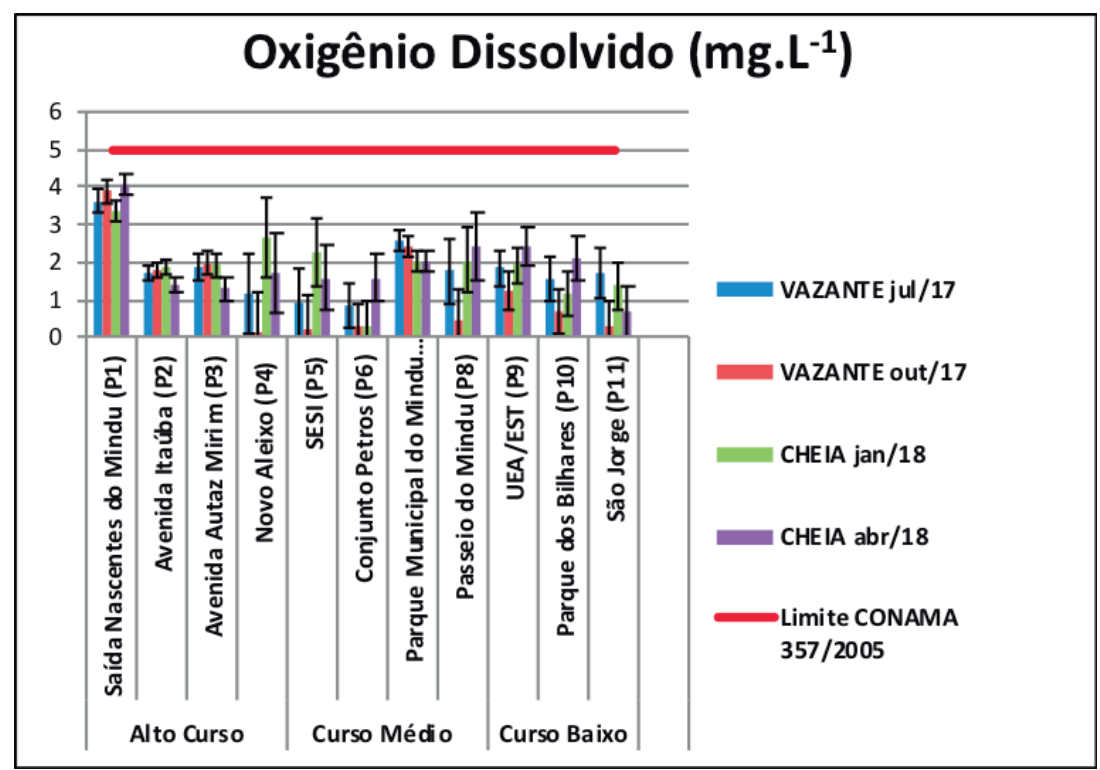

Fonte: Elaboração própria do autor (2018).

A média aritmética dos pontos avaliados apresentou oscilação entre $0,76-3,73 \mathrm{mg} . \mathrm{L}^{-1} \mathrm{com}$ desvio padrão possuindo maiores valores no ponto 
P4, P5 e P8 com variação entre 0,20 - 1,04 (Figura 13) com predomínio de baixas concentrações no alto curso do igarapé, sobretudo no período de vazante, onde a concentração dos poluentes é maior em virtude da redução do volume das águas.

Nas águas próximas ao ponto P1 - Saída nascentes do Mindu na Figura 14 (A) foi observado uma obstrução nas águas oriunda de um bueiro recém construido nas irremediações do Parque Nascentes do Mindu, que possui 4 (quatro) nascentes íntegras do igarapé do Mindu. Na seta azul (Figura 14 - A) é possivel ver a água que provém das nascentes e se mistura logo a seguir com as águas do esgoto. No ponto localizado no conjunto Petros (P6) conforme a seta azul na Figura 14 (B) foi identificado uma rota de dejetos orgânicos que se seguia até o leito do igarapé.

Figura 14 - Identificação de bueiro recém-construído nas proximidades das nascentes do Mindu (A) e presença de dejetos orgânicos no ponto P6 no Conjunto Petros (B)

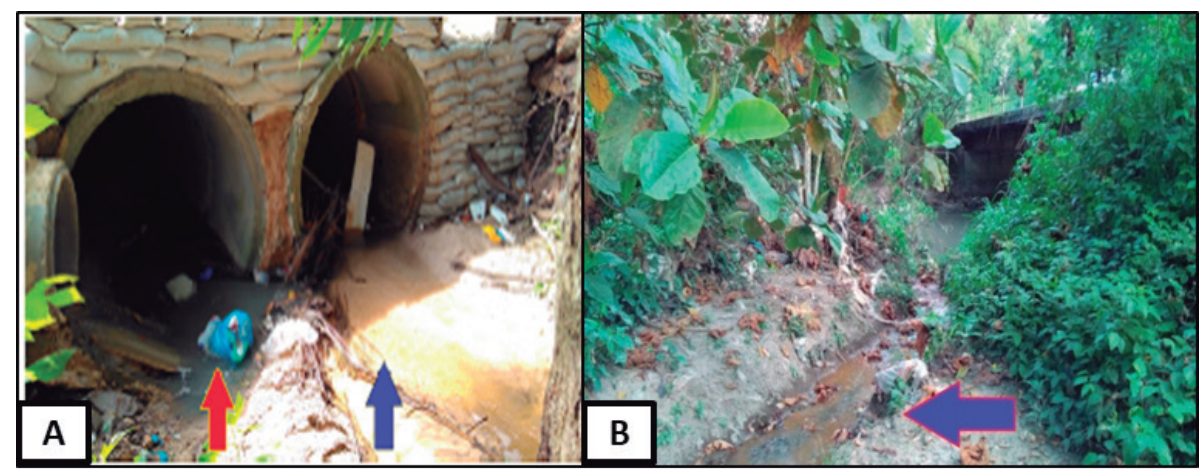

Fonte: Elaboração própria do autor (2018).

\section{Turbidez}

Com relação à turbidez, os maiores valores se deram no ponto $\mathrm{P} 4$ na vazante e P5 no período de cheia. Os resultados oscilaram entre 5,02 - 181 NTU com predominância dos maiores valores no período de cheia. De acordo com a resolução CONAMA 357/05 para rios de classe II a turbidez é de até no máximo 100 NTU. Apenas os pontos P4 e P5 apresentaram resultados fora de especificação, os demais foram enquadrados com 
resultados inferiores aos limites da legislação conforme linha vermelha da Figura 15.

Almeida et al. (2017, pg. 213) obteve resultados de até 68 NTU para águas das nascentes, onde destacou que o processo de erosão e/ou sólidos é reduzido pela mata pluvial, consequentemente a carga de sedimentos é baixa e o curso é mais transparente. Este mesmo autor obteve valores de Turbidez variando de 458 a 496 NTU nos trechos do curso médio ao baixo, com maiores resultados obtidos nas águas do Corredor Ecológico Urbano do Igarapé Mindu (Médio Curso). No gráfico da Figura 15 é apresentado os resultados obtidos para a turbidez das águas no período avaliado.

Figura 15 - Gráfico do parâmetro analisado turbidez das águas.

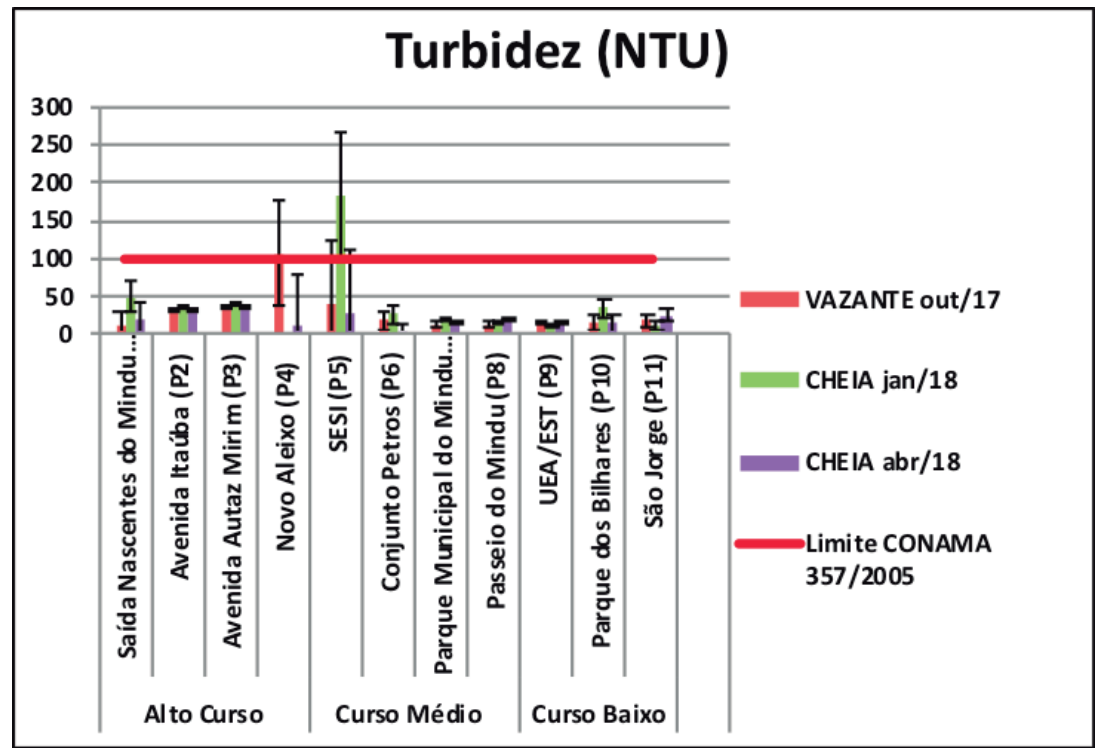

Fonte: Elaboração própria do autor (2018).

A média dos valores encontrada foi entre 14,83 - 82,67 NTU com maior desvio padrão nos pontos P4 e P5 conforme gráfico da Figura 15. A alta concentração de turbidez é ocasionada pela grande quantidade de despejos industriais, domésticos e resíduos sólidos que se solubilizam nas águas na forma de sólidos em suspensão que conferem obstáculos a passagem da luz, remoção das mata ciliar e aumento do processo erosivo nas águas, sobretudo através do aumento do assoreamento, que além de 
impactos na turbidez das águas ainda contribuem para a baixa concentração de oxigênio dissolvido, empecilho para a realização da fotossíntese com redução da quantidade de luz disponível para os seres fotossintéticos presentes nas águas.

\section{Nitrogênio Amoniacal (Amônia)}

A média dos resultados apresentou-se entre $1,28-9,83 \mathrm{mg} . \mathrm{L}^{-1} \mathrm{e}$ a variação do desvio padrão encontrada foi entre $0,14-2,82$ conforme gráfico da Figura 16. A maior dispersão dos dados foi encontrada no alto curso do igarapé do Mindu e nos pontos P5 e P6 do médio curso do igarapé. Nascimento (2011, pg.30) analisando as águas do igarapé do Mindu em coleta realizada no ano de 2010 destacou que na avaliação dos pontos de máxima contaminação do Igarapé do Mindu $\left(03^{\circ} 09^{\prime} \mathrm{S}, 60^{\circ} 01^{\prime} \mathrm{W}\right)$, a água apresentava uma tonalidade esverdeada e odor característico de matéria orgânica em decomposição. Em seu experimento aferiu para análise de nitrogênio amoniacal (amônia) médias de 10,08 mg.L-1 .

Figura 16 - Gráfico do parâmetro analisado nitrogênio amoniacal (Amônia) nos pontos de P1 a P11.

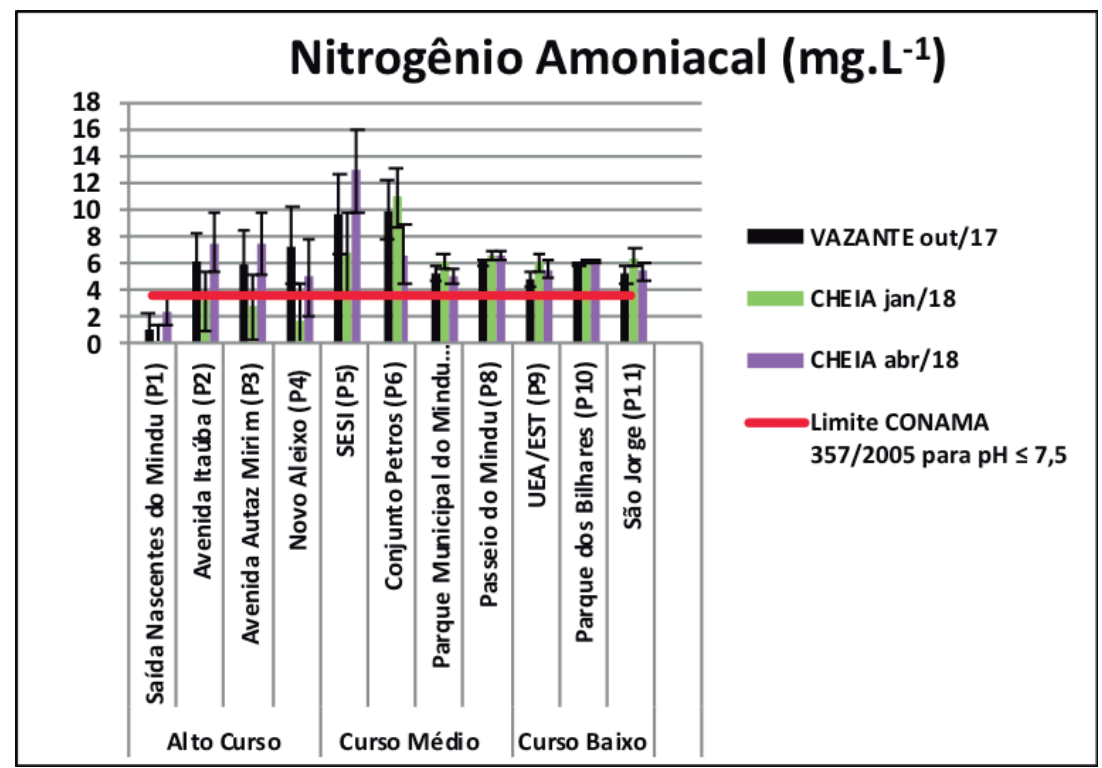

Fonte: Elaboração própria do autor (2018). 
Os valores de nitrogênio amoniacal $\left(\mathrm{N}^{-\mathrm{NH}_{3}}\right)$ de acordo com a resolução CONAMA 357/05, devem manter-se em níveis inferiores a 3,7 (mg.L $\mathrm{L}^{-1} \mathrm{~N}-\mathrm{NH}_{3}$ ) quando o valor do $\mathrm{pH}$ se encontrar igual ou inferior a 7,5. Neste estudo todos os pontos analisados de P1 a P11 apresentaram pH abaixo de $<7,2$. Os resultados obtidos para nitrogênio amoniacal foram analisados em outubro de 2017 e janeiro de 2018. No mês de outubro de 2017 excetuando-se o ponto P1 - Saída nascentes do Mindu com valor obtido de $1,14 \mathrm{mg} . \mathrm{L}^{-1}$, todos os outros pontos apresentaram valores superiores a $>3,7 \mathrm{mg} . \mathrm{L}^{-1}$ de amônia, chegando a até $10,0 \mathrm{mg} . \mathrm{L}^{-1}$ no ponto P6 - no conjunto Petros. Para os resultados de janeiro de 2018 apenas os pontos $\mathrm{P} 1, \mathrm{P} 2$, P3, e P4 apresentaram resultados inferiores a $<3,7 \mathrm{mg} . \mathrm{L}^{-1} \mathrm{de}$ amônia e enquadrados a resolução CONAMA 357/2005; os demais pontos de P5 a P11 apresentaram valores superiores a $>3,7$ mg. $\mathrm{L}^{-1}$ de amônia e em desacordo ao que preconiza a legislação vigente para este parâmetro, chegando a valores de até $12,9 \mathrm{mg} . \mathrm{L}^{-1}$ no ponto P5 - SESI.

\section{Fosfato Total}

O parâmetro fosfato total foi avaliado apenas no período de cheia do igarapé do Mindu. Apresentou oscilação entre 0,3 - 53,5 mg. $\mathrm{L}^{-1}$ conforme gráfico da Figura 17, com maiores valores encontrados nas análises do ponto P4 e P6 no período de cheia. Todas as amostras analisadas dos pontos de P1 a P11 (Figura 17) coletados para análise de fosfato total encontraram-se acima dos valores permitidos pela Resolução $N^{0} 357 / 05$ do CONAMA para corpos d'agua Classe Tipo II, que é de $0,1 \mathrm{mg} . \mathrm{L}^{-1} \mathrm{em}$ ambiente lótico para fósforo inorgânico (fosfatos).

$\mathrm{O}$ desvio padrão apresentou maior valor também no ponto $\mathrm{P} 4$ e oscilação entre 0,99 - 37,05 conforme gráfico da Figura 17. Este ponto P4, inclusive tem concentrado os maiores valores de $\mathrm{pH}$, turbidez, fosfato, sulfetos, e presença de sólidos totais dissolvidos nas águas. Fernandes et al. (2016, pg. 143) analisando águas do Igarapé do Educandos que assim como o Igarapé do Mindu absorve contribuições de efluentes domésticos e industriais em seu curso (PINTO et al., 2009, pg. 636), obteve concentrações de fosfato total oscilando entre $2,1-3,15 \mathrm{mg} . \mathrm{L}^{-1}$ acima do preconizado pela legislação CONAMA 357 /2005. 
Figura 17 - Gráfico do parâmetro analisado fosfato total nos pontos de P1 a P11.

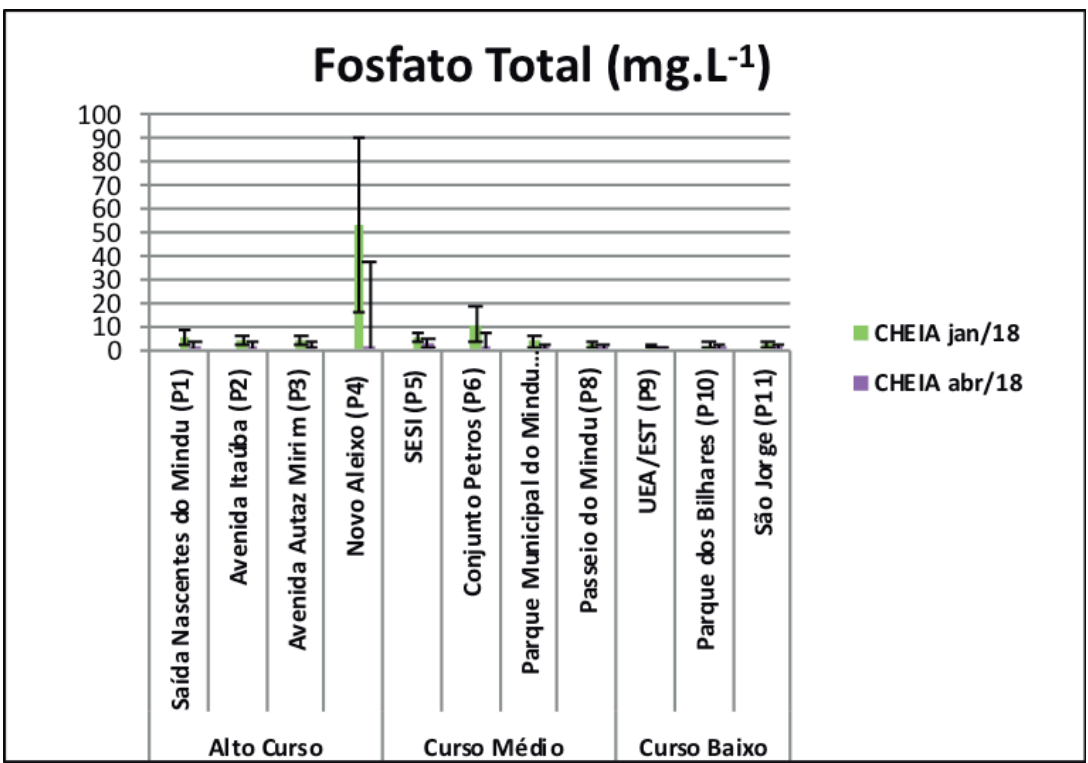

Fonte: Elaboração própria do autor (2018).

\section{Sulfetos}

A presença de sulfatos, sulfetos e sulfitos são comumente encontrados nos esgotos domésticos e apresentam-se sob a forma reduzida nas águas naturais. Esta análise foi realizada de forma prévia com vista a identificação destes compostos nas águas, haja visto que o lançamento de esgotos domésticos tem sido problema decorrente na cidade de Manaus (PINTO et al, 2009, pg. 636). Conforme gráfico da Figura 18, o destaque fica por conta do ponto $\mathrm{P} 4$, localizado no Novo Aleixo, cujo resultado apresentou concentração de $0,679 \mathrm{mg} . \mathrm{L}^{-1} \mathrm{em}$ janeiro de 2018. 
Figura 18 - Gráfico do parâmețro analisado de sulfetos.

\begin{tabular}{|c|c|c|c|c|c|c|c|c|c|c|}
\hline & & & & & & & & & & \\
\hline & & & & & & & & & & \\
\hline & & & & & & & & & & \\
\hline$I_{\pi}$ & & - & & $\mathrm{I}_{\mathrm{T}}$ & $I_{T}$ & $\mp$ & - & - & $I_{\boldsymbol{I}}$ & - \\
\hline 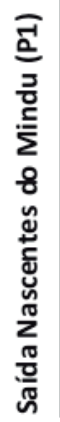 & 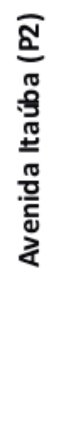 & 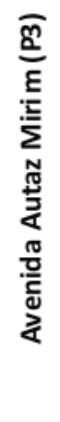 & $\begin{array}{l}\bar{y} \\
\frac{0}{0} \\
\frac{0}{4} \\
\frac{0}{4} \\
\frac{0}{2} \\
\frac{0}{2}\end{array}$ & 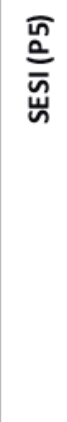 & 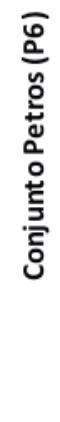 & 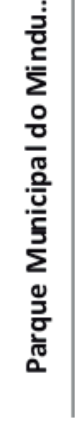 & 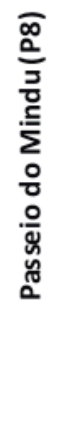 & 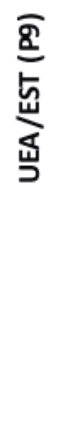 & 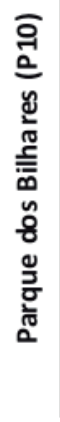 & 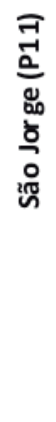 \\
\hline
\end{tabular}

CHEIA jal

CHEIA ab

Fonte: Elaboração própria do autor (2018).

$\mathrm{Na}$ avaliação estatística do desvio padrão os valores oscilaram entre $0,0021-0,46$. Conforme resultados obtidos, supostamente a presença de sulfetos ainda que discreta nas águas é um indicativo da oxidação e conversão da molécula de enxofre através da disposição dos poluentes lançados nas águas, com maior predominância da disposição de efluentes domésticos (esgoto), resíduos sólidos (lixo) e de efluentes industriais que possuem composições diversas em seus resíduos gerados (sulfatos, sulfetos, sulfitos), estando portanto disponíveis como despejo nas águas do igarapé para diluição e autodepuração, ainda que demasiadamente prolongada e apresentando grande risco para os organismos aquáticos e assimilação da cadeia trófica.

\section{Considerações finais}

A descaracterização por poluição e contaminação das águas naturais do igarapé do Mindu ainda nos trechos de alto curso e médio curso implica no carreamento dos poluentes até o rio Negro, este um rio de abastecimento público da cidade de Manaus que recebe toda a carga orgânica dos igarapés da bacia hidrográfica do São Raimundo, entre eles o seu principal 
curso, o igarapé do Mindu. Os valores mais baixos de oxigênio dissolvido (próximos de zero), mais altos de nitrogênio amoniacal e concentração de fosfatos, estão concentrados no ponto P6 - no Conjunto Petros, parâmetros estes relacionados com o lançamento de dejetos orgânicos e de fontes industriais. Os piores resultados obtidos para os parâmetros de turbidez das águas, sulfetos e fosfatos, foram encontrados no ponto P4 - no Novo Aleixo, parâmetros estes relacionados com o carreamento de sólidos, assoreamento do leito, e lançamentos de efluentes industriais, sobretudo pela presença de sulfetos em alta concentração que é um indicativo de diluição de efluentes domésticos nas águas.

Analisando os pontos de maior influência antrópica para os resultados obtidos nos pontos (P1 a P11) da nascente até a foz do Igarapé do igarapé do Mindu, se verificou que a oscilação nos parâmetros avaliados apresenta grande incidência de transporte de carga de poluentes e contaminantes orgânicos haja visto os altos valores obtidos de $\mathrm{pH}$ de $6,44-$

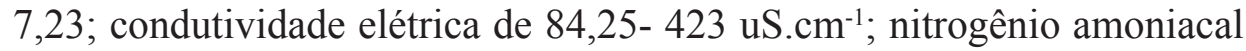
de 1,14-12,9 mg. $\mathrm{L}^{-1}$ e baixos valores de oxigênio dissolvido oscilando de valores $<2,64 \mathrm{mg} . \mathrm{L}^{-1} \mathrm{em}$ trechos (P2-P11) excetuando-se o ponto das nascentes (P1) contribuem para o acréscimo da matéria orgânica nas águas e descaracterização das características naturais das águas. A presença de nitrogênio amoniacal, fosfatos e sulfetos em concentrações acima das condições naturais das águas, o que pode estar associado ao alto grau de contaminação das águas por lançamentos de dejetos orgânicos e efluentes industriais, é reforçada pelos valores obtidos de nitrogênio amoniacal e fosfato total que apresentam em sua grande maioria dentre estes 11 pontos analisados, valores em desacordo ao que preconiza a legislação CONAMA $357 / 2005$ para rios de classe II.

Os resultados elencados nestes trechos urbanos podem ainda surgir como ponto de prevenção para o desenvolvimento de políticas públicas de preservação, proteção das nascentes e práticas de educação ambiental, fato outrora discutido Borges e Santos (2011, pg. 3) em seu projeto de gestão ambiental em área de nascente do igarapé do Mindu.

A presença nas águas de contaminantes críticos como fosfato, sulfetos e nitrogênio amoniacal, com diversos destes pontos analisados em desacordo ao que preconiza a legislação vigente, serve como vigilância para rever o planejamento e disposição dos resíduos domésticos e industriais 
que estão sendo lançados no leito do igarapé, haja visto que em tempos de sustentabilidade e meio ambiente equilibrado seja incentivado a busca de alternativas para aperfeiçoar o saneamento básico na cidade de Manaus, cidade que embora possua abundância de águas, apresenta fragilidades em trechos hídricos urbanos, como o apresentado neste estudo.

\section{Referências}

Agência Nacional de Águas (2012). Panorama da Qualidade das Águas Superficiais do Brasil. Disponível em: $<$ http://ana.gov.br $>$.

Almeida, F.R; Leite, J.C; Alves, C.N; Deus, R.J.A. (2017). Environmental diagnostic of the spa park 10 de Novembro at Igarapé Mindú in Manaus. ITEGAM-JETIA, v.3, n²10, pp.204-219.

APHA (2005). American Public Health Association. Standard methods for the examination of water and wastewater, 21 st ed. Washington.

Borges, M. G. M. e Santos, E. C. (2011). Gestão ambiental e preservação de nascentes: um estudo para elaboração de políticas de gestão ambiental da nascente do Igarapé do Mindú, no bairro Cidade de Deus - Manaus/AM. Revista Geográfica de América Central, Número Especial EGAL, Costa Rica, 2 (47E), pp.1-12.

Brasil (2005). Resolução CONAMA $n^{\circ}$ 357/2005 "Dispõe sobre a classificação dos corpos de água e diretrizes ambientais para o seu enquadramento, bem como estabelece as condições e padrões de lançamento de efluentes, e dá outras providências."- Data da legislação: 17/03/2005 - Publicação DOU: 18/03/2005.

Cassiano, K, R, M. (2013). Análise Geográfica de Áreas de Risco na Bacia Hidrográfica do Igarapé do Mindu - Manaus (AM). Dissertação do Mestrado em Geografia. Universidade Federal de Santa Catarina, Florianópolis-SC. 103p.

CETESB. (2011). Companhia de Tecnologia de Saneamento Ambiental. Resolução $n^{\circ}$ 724/2011 -Guia Nacional de coleta e preservação de amostras: água, sedimentos, comunidades aquáticas e efluentes líquidos. São Paulo: CETESB: Brasília: ANA.

Diego, O.S; Nascimento, M.G; Alvalá, R.C.S; (2015). Influência do crescimento urbano sobre o microclima de Manaus e Belém: Um estudo observacional. Revista Brasileira de Geografia Física, v.8, $\mathrm{n}^{\circ} 4$, pp.1109-1124. 
Fernandes, E.P; Stehlgens, L.S; Santos, S.O.; Chaves, E.V. (2016). Avaliação do Comportamento Hidroquímico de Fosfato das Águas do Igarapé da Bacia do Educandos no Município de Manaus. Anais do I Congresso de Ciência, Educação e Pesquisa Tecnológica. IFAM/ CONCEPT, Manaus-AM.

Ferreira, S.J.F.; Miranda, S.A.F.; Silva, C.C; Marques Filho, A.O; (2012). Efeito da pressão antrópica sobre igarapés na Reserva Florestal Adolpho Ducke, área de floresta na Amazônia Central. Acta Amazônica, v.42, n² , pp.533-540.

INSTITUTO TRATA BRASIL; (2018). Ranking do Saneamento 2018. São Paulo-SP, 118p.

MELO, E. G. F.; SILVA, M. S. R.; MIRANDA, S. A. F. Influência antrópica sobre águas de igarapés na cidade de Manaus-Amazonas. Caminhos de geografia, v.5, n²16, pp.40-47, 2005.

Nascimento, J.H.P. Efeitos e exposição de ovos e larvas de Osteocephalus taurinus Steindachner, 1862 - (Anura, Hylidae) à água contaminada de dois igarapés de Manaus-AM: Toxidade aguda e crônica. Dissertação de Mestrado. Manaus-AM: Ufam, 45p, 2011.

Pinto, A. G. N.; Horbe, A.M.C.; Silva, M.S.R.; Miranda, S.A.F.; Pascoaloto, D.; Santos, H.M.C. (2009). Efeitos da ação antrópica sobre a hidrogeoquímica do rio Negro na orla de Manaus/AM. Acta Amazônica, v.39, n³, pp.627-638.

Prefeitura Municipal de Manaus (2006). Decreto municipal $N^{\circ} 8.351$, de 17 de março de 2006. Institui o Parque Municipal Nascentes (PMNM), Centro de Vigilância da Nascente.

Prefeitura Municipal de Manaus (2008) Plano de Manejo do Corredor Ecológico Urbano do Igarapé do Mindu/Parque Municipal do Min$d u$. Manaus.

Prefeitura Municipal de Manaus. (1993). Lei municipal N²19, novembro de 1993. Criação do Parque Municipal do Mindu.

Sperling, M. V. (2005). Introdução à qualidade da água e ao tratamento de esgoto. Belo Horizonte. Ed. DESA/UFMG, pp. 452.

SIOLI, H.; KLINGE, H. Solos, tipos de vegetação e águas na Amazônia. Boletim geográfico. v.79, pp.27-41, 1962. 